\title{
Pretreatment Anterior Choroidal Artery Infarction Predicts Poor Outcome after Thrombectomy in Intracranial ICA Occlusion
}

\author{
(D)B.H. Baek, (D)Y.Y. Lee, (D)S.K. Kim, and (DW. Yoon
}

\begin{abstract}
BACKGROUND AND PURPOSE: Predictors of outcome after endovascular thrombectomy have not been investigated adequately in patients with intracranial ICA occlusions. This study aimed to assess the impact of anterior choroidal artery infarction in pretreatment DWI on the outcome of patients with acute intracranial ICA occlusion who underwent thrombectomy.
\end{abstract}

MATERIALS AND METHODS: This study included 113 patients with acute intracranial ICA occlusion who underwent DWI followed by thrombectomy between January 2011 and July 2016. Characteristics and outcomes were compared between the groups positive and negative for anterior choroidal artery infarction and patients with good outcomes (90-day mRS 0-2) and poor outcomes (mRS 3-6). Binary logistic regression analyses were performed to identify independent predictors of a good outcome.

RESULTS: On pretreatment DWI, anterior choroidal artery infarction was observed in 60 patients (53.1\%). Good outcomes were significantly less frequent in the group positive for anterior choroidal artery infarction than in the group negative for it $(25 \%$ versus $49.1 \%, P=$ .008). Parenchymal hemorrhage occurred only in the group positive for anterior choroidal artery infarction ( $13.3 \%$ versus $0 \%, P=.007)$. In the multivariate logistic regression analysis, independent predictors of good outcome were an absence of anterior choroidal artery infarction (OR, 0.333; 95\% Cl, 0.135-0.824; $P=.017$ ) and successful reperfusion (OR, 5.598; 95\% Cl, 1.135-27.604; $P=.034$ ).

CONCLUSIONS: Pretreatment anterior choroidal artery infarction is associated with parenchymal hemorrhage and poor outcome after thrombectomy in patients with acute intracranial ICA occlusion. In addition, the absence of anterior choroidal artery infarction and successful reperfusion were independent predictors of good outcome after thrombectomy in acute intracranial ICA occlusion.

D espite recent advances in endovascular therapy for occlusion of large intracranial vessels, occlusion of the intracranial ICA is still associated with poor clinical outcomes mainly due to a substantial clot burden and poor collateral circulation. ${ }^{1,2}$ Recent studies have reported that the rate of a good outcome is 34\%-39\% after endovascular thrombectomy in patients with intracranial ICA occlusions. ${ }^{1,2}$ Understanding the prognostic factors after endovascular thrombectomy may help refine patient-selection criteria and improve treatment outcomes in this specific group of patients. Although a few studies have investigated the predictors of outcomes following thrombectomy in patients with acute anterior circulation stroke, ${ }^{2,3}$ such predictors have not been in-

Received April 4, 2019; accepted after revision June 13.

From the Department of Radiology, Chonnam National University Medical School, Gwangju, Republic of Korea.

Please address correspondence to Woong Yoon, MD, PhD, Department of Radiology, Chonnam National University Medical School, Chonnam National University Hospital, 42 Jebong-ro, Dong-gu, Gwangju, 61469, Republic of Korea; e-mail: radyoon@jnu.ac.kr

http://dx.doi.org/10.3174/ajnr.A6126 vestigated adequately in patients with acute intracranial ICA occlusions.

Occlusion of the intracranial ICA may compromise the origin of the anterior choroidal artery, causing anterior choroidal artery territory infarction. The anterior choroidal artery arises from the terminal segment of the ICA and supplies critical brain structures, including the uncus, amygdala, posterior limb of the internal capsule, lateral thalamus, tail of the caudate nucleus, rostral part of the hippocampus, and the lateral choroid plexus. ${ }^{4-8}$ Anterior choroidal artery territory infarction usually has a poor prognosis. Lee et $\mathrm{al}^{7}$ reported that $88 \%$ of patients with full anterior choroidal artery territory infarct or partial infarct involving the anterior choroidal artery territory other than the medial temporal lobe had a poor 90-day outcome (mRS 3-6). Anterior choroidal artery infarction can be found on imaging before endovascular thrombectomy in patients with acute intracranial ICA occlusion. However, the prognostic impact of anterior choroidal artery infarction observed on pretreatment imaging has not yet been investigated in patients with intracranial ICA occlusions, to our knowledge. Therefore, the purpose of this study was to investigate the prognostic 
factors of treatment outcomes following endovascular thrombectomy in patients with acute stroke due to intracranial ICA occlusion and the impact of anterior choroidal artery infarction on pretreatment DWI on treatment outcomes in these patients.

\section{MATERIALS AND METHODS \\ Patients}

From January 2011 to July 2016, a total of 380 patients presenting with acute anterior circulation stroke due to occlusion of the intracranial ICA $(n=116)$ or MCA $(n=264)$ were treated with endovascular thrombectomy at a comprehensive stroke center. Of 116 patients with ICA occlusion, 3 without pretreatment DWI data were excluded. Thus, a total of 113 patients with acute intracranial ICA occlusion who had pretreatment DWI before thrombectomy were enrolled in the study.

All patients underwent nonenhanced cranial CT and multimodal MR imaging, which included DWI, gradient-echo imaging, FLAIR, and 3D-TOF-MRA before endovascular therapy. Intravenous rtPA was administered to eligible patients. The inclusion criteria for endovascular therapy were the following: femoral artery puncture initiated within 6 hours of stroke onset, a baseline NIHSS score of $\geq 4$, no evidence of intracranial hemorrhage on pretreatment imaging, and infarct volume less than one-third of the MCA territory on pretreatment imaging. Clinical and radiologic data were collected prospectively in the stroke data base at our institution. This study was approved by our institutional ethics committee.

\section{DWI Assessment}

Pretreatment MR imaging examinations were performed using a 1.5T MR imaging scanner (Signa HDxt; GE Healthcare, Milwaukee, Wisconsin). DWI sequences were obtained in the axial plane using a single-shot, spin-echo EPI technique with the following parameters: $\mathrm{TR}=9000 \mathrm{~ms}, \mathrm{TE}=80 \mathrm{~ms}$, section thickness $=4$ $\mathrm{mm}$, intersection gap $=0 \mathrm{~mm}, \mathrm{FOV}=260 \times 260 \mathrm{~mm}$, and b-values $=0$ and $1000 \mathrm{~s} / \mathrm{mm}^{2}$. On DWI, anterior choroidal artery infarction was defined as an acute infarction located in the uncus, amygdala nucleus, posterior limb of the internal capsule, tail of the caudate nucleus, medial segment of the globus pallidus, lateral thalamus, optic radiation, cerebral peduncle, or hippocampus. ${ }^{4}$ DWI was evaluated retrospectively by 2 neuroradiologists who were blinded to the patients' clinical and angiographic information. Two readers also assessed the DWI-ASPECTS. Conclusions were reached by the consensus of 2 readers in the case of disagreement.

\section{Endovascular Thrombectomy}

Cerebral angiography and endovascular therapy were performed with the patient under local anesthesia. Intracranial ICA was defined as part of the ICA segment from the ophthalmic segment to the T-bifurcation. Intracranial ICA occlusion was confirmed by catheter DSA in all patients. Endovascular thrombectomy with either a Solitaire stent (Covidien, Irvine, California) or Trevo stent (Stryker, Kalamazoo, Michigan) was performed as the frontline thrombectomy technique. If the frontline thrombectomy was unsuccessful in achieving reperfusion, contact aspiration thrombectomy was performed using an intermediate catheter or a
Penumbra reperfusion catheter (Penumbra, Alameda, California). ${ }^{9,10}$ A balloon-guide catheter was not used in this study. When a patient had a simultaneous tandem occlusion at the proximal cervical segment of the ICA, carotid angioplasty and stent placement were performed before intracranial endovascular thrombectomy. Intracranial angioplasty with or without stent placement was also performed when underlying severe (>70\%) intracranial atherosclerotic stenosis was found at the occlusion site. Patients who underwent either intracranial angioplasty/stent placement or carotid stent placement received aspirin and clopidogrel immediately following the endovascular treatment. In these patients, dual-antiplatelet therapy was continued for at least 3 months after discharge. Intracranial reperfusion status was assessed on the final angiogram and classified according to the modified TICI scale. ${ }^{11}$ Successful reperfusion was defined as a modified TICI grade of $2 \mathrm{~b}$ or 3 .

\section{Outcome Measures}

All patients underwent nonenhanced CT immediately and 24 hours following endovascular thrombectomy. Intracerebral hemorrhage was assessed on posttreatment CT scans and classified as either hemorrhagic infarction or parenchymal hemorrhage according to the European Cooperative Acute Stroke Study II (ECASS II) criteria. ${ }^{12}$ Symptomatic hemorrhage was defined as any intracranial hemorrhage that caused neurologic deterioration (NIHSS score increase of $\geq 4$ points). Stroke subtype was determined at the time of discharge by a stroke neurologist on the basis of the Trial of ORG 10172 in Acute Stroke Treatment (TOAST) classification. ${ }^{13}$ Clinical outcomes were assessed by a stroke neurologist using the mRS during an outpatient visit 3 months posttreatment. When patients were unable to visit, the mRS score was assessed via telephone interview. A good outcome was defined as mRS score of $0-2$.

\section{Statistical Analysis}

Continuous variables were presented as medians and interquartile ranges, whereas discrete variables were presented as numbers and percentages. The $\chi^{2}$ test or Fisher exact test was used for categoric variables, and the Mann-Whitney $U$ test was used to compare continuous variables. We compared differences in patient characteristics and treatment outcomes between the groups positive and negative for anterior choroidal artery infarction and between patients with good and poor outcomes. Binary logistic regression analysis was performed to identify independent predictors of a good 90-day outcome. Finally, the associations between characteristics and good 90-day outcome were investigated only among patients with successful reperfusion. Variables with a $P$ value of $<.05$ from the univariate analysis and those considered clinically relevant (age and baseline NIHSS) were included for the multivariate analysis. Statistical analysis was performed using SPSS software (Version 23.0; IBM, Armonk, New York) with $P<$ .05 considered significant.

\section{RESULTS}

Data from 113 patients (53 men and 60 women; median age, 74 years) were analyzed. The median baseline NIHSS score was 14. Intravenous rtPA was administered in $53 \%$ of patients. The 


\begin{tabular}{|c|c|c|c|c|}
\hline & $\begin{array}{l}\text { All Patients } \\
\qquad(n=113)\end{array}$ & $\begin{array}{c}\text { Positive for Anterior } \\
\text { Choroidal Artery } \\
\text { Infarction }(n=60)\end{array}$ & $\begin{array}{c}\text { Negative for Anterior } \\
\text { Choroidal Artery } \\
\text { Infarction }(n=53)\end{array}$ & $P$ \\
\hline Age (yr) & $74(63-78)$ & $73(62.25-78)$ & $74(65-80.50)$ & .152 \\
\hline Sex, male & $53(46.9)$ & $26(43.3)$ & $27(50.9)$ & .419 \\
\hline \multicolumn{5}{|l|}{ Risk factors } \\
\hline Hypertension & $76(67.3)$ & $41(68.3)$ & $35(66)$ & .795 \\
\hline Diabetes mellitus & $31(27.4)$ & $20(33.3)$ & $11(20.8)$ & .135 \\
\hline Dyslipidemia & $31(27.4)$ & $16(26.7)$ & $15(28.3)$ & .846 \\
\hline Smoking & $25(22.1)$ & $8(13.3)^{\prime}$ & $17(32.1)$ & .017 \\
\hline Atrial fibrillation & 69 (61.1) & $38(63.3)$ & $31(58.5)$ & .598 \\
\hline Coronary artery disease & 19 (16.8) & 10 (16.7) & $9(16.9)$ & .964 \\
\hline Previous stroke or TIA & $16(14.2)$ & $7(11.7)$ & $9(16.9)$ & .419 \\
\hline Congestive heart failure & $7(6.2)$ & $4(6.7)$ & $3(5.7)^{\prime}$ & 1.000 \\
\hline Intravenous thrombolysis & $60(53.1)$ & $35(58.3)$ & $25(47.2)$ & .235 \\
\hline DWI-ASPECTS & $7(5-8)$ & $6(4-8)$ & $7(5.5-8)$ & .059 \\
\hline Time to puncture (median) (IQR) (min) & $220(160-290)$ & $205(151.25-297.50)$ & $240(179-298)$ & .211 \\
\hline Procedure duration (min) & $35(25-50)$ & $35(25-50)$ & $42(23-53.5)$ & .490 \\
\hline Time to reperfusion (min) & $253(197-337)$ & $236.50(186.25-332.00)$ & $282(206.5-350)$ & .214 \\
\hline Baseline NIHSS score & $14(11-17)$ & $14(12-17)$ & $15(10-17)$ & .701 \\
\hline Underlying intracranial atherosclerotic stenosis & $12(10.6)$ & $4(6.7)$ & $8(15.1)$ & .221 \\
\hline Cervical ICA tandem occlusion & $10(8.8)$ & $3(5)$ & $7(13.2)$ & .185 \\
\hline Stroke subtype & & & & .509 \\
\hline Cardioembolism & $74(65.5)$ & $42(70)$ & $32(60.4)$ & \\
\hline Large-artery atherosclerosis & 18 (15.9) & $6(10)$ & $12(22.6)$ & \\
\hline Undetermined & $19(16.8)$ & $12(20)$ & $7(13.2)$ & \\
\hline Other & $2(1.8)$ & 0 & $2(3.8)$ & \\
\hline
\end{tabular}

Note:-IQR indicates interquartile range.

a Values are presented as No. (\%) or median (IQR).

Table 2: Comparison of treatment outcomes between patients with and without anterior choroidal artery infarction ${ }^{a}$

\begin{tabular}{lcccc}
\hline & $\begin{array}{c}\text { All Patients } \\
(\boldsymbol{n}=113)\end{array}$ & $\begin{array}{c}\text { Positive for } \\
\text { Anterior Choroidal } \\
\text { Artery Infarction } \\
(\boldsymbol{n}=\mathbf{6 0})\end{array}$ & $\begin{array}{c}\text { Negative for } \\
\text { Anterior Choroidal } \\
\text { Artery Infarction } \\
(\boldsymbol{n}=53)\end{array}$ & $\boldsymbol{P}$ \\
\hline Successful reperfusion & $89(78.8)$ & $45(75)$ & $44(83.0)$ & .298 \\
90-Day mRS 0-2 & $41(37.2)$ & $15(25)$ & $26(49.1)$ & .008 \\
Parenchymal hemorrhage & $8(7.1)$ & $8(13.3)$ & 0 & .007 \\
Symptomatic hemorrhage & $4(3.5)$ & $4(6.7)$ & 0 & .121 \\
90-Day mortality & $12(10.6)$ & $6(10)$ & $6(11.3)$ & .820 \\
\hline
\end{tabular}

${ }^{a}$ Values are presented as No. (\%).

stroke subtype was cardioembolism in 74 patients $(65.5 \%)$, large-artery atherosclerosis in 18 patients (15.9\%), undetermined in 19 patients $(16.8 \%)$, and other in 2 patients $(1.8 \%)$. The median DWI-ASPECTS was 7. Twelve patients (10.6\%) had underlying severe intracranial atherosclerotic stenosis, and 10 patients $(8.8 \%)$ underwent carotid artery stent placement before endovascular thrombectomy. Overall, successful reperfusion was achieved in $79 \%$ of patients (89/113), and a good 90 -day outcome, in $37 \%$ of patients (41/113). Parenchymal hemorrhage occurred in $7.1 \%$ of patients $(8 / 113)$, and symptomatic hemorrhage, in $3.5 \%$ (4/113). The 90 -day mortality rate was $10.6 \%(12 / 113)$.

\section{Association between Anterior Choroidal Artery Territory Infarction and Treatment Outcomes}

Anterior choroidal artery infarction was observed in $53.1 \%$ of patients $(60 / 113)$ on pretreatment DWI, distributed as follows: the medial temporal lobe including the uncus and amygdala nucleus in 57 patients, the posterior limb of the internal capsule in 36 patients, tail of the caudate nucleus in 12 patients, optic radiation in 7 patients, lateral thalamus in 6 patients, medial pallidum in 5 patients, hippocampus in 2 patients, and cerebral peduncle in 1 patient. Among these, 21 patients (35\%) had anterior choroidal artery infarction confined to the medial temporal lobe (uncus, amygdala, or both). Comparisons of the clinical and procedural characteristics between the groups positive and negative for anterior choroidal artery infarction are shown in Table 1. Smoking history was less frequent in the group positive for anterior choroidal artery infarction than in the group negative for it. No significant differences were found between the 2 groups in other characteristics.

Comparisons of the treatment outcomes between the groups positive and negative for anterior choroidal artery infarction are shown in Table 2. A good 90-day outcome was significantly less frequent in the group positive for anterior choroidal artery infarction than the group negative for it ( $25 \%$ versus $49.1 \%, P=.008$ ). Parenchymal hemorrhage occurred only in the group positive for anterior choroidal artery infarction ( $13.3 \%$ versus $0 \%, P=.007)$. Parenchymal hemorrhage occurred in the anterior choroidal artery territory in 3 patients (all in the uncus and amygdala) (Fig 1) and in other locations in 5 patients (basal ganglia in 5 patients, frontal lobe in 2 patients, and lateral temporal lobe in 1 patient). All 3 patients with parenchymal hemorrhage in the anterior choroidal artery territory had concomitant parenchymal hemor- 

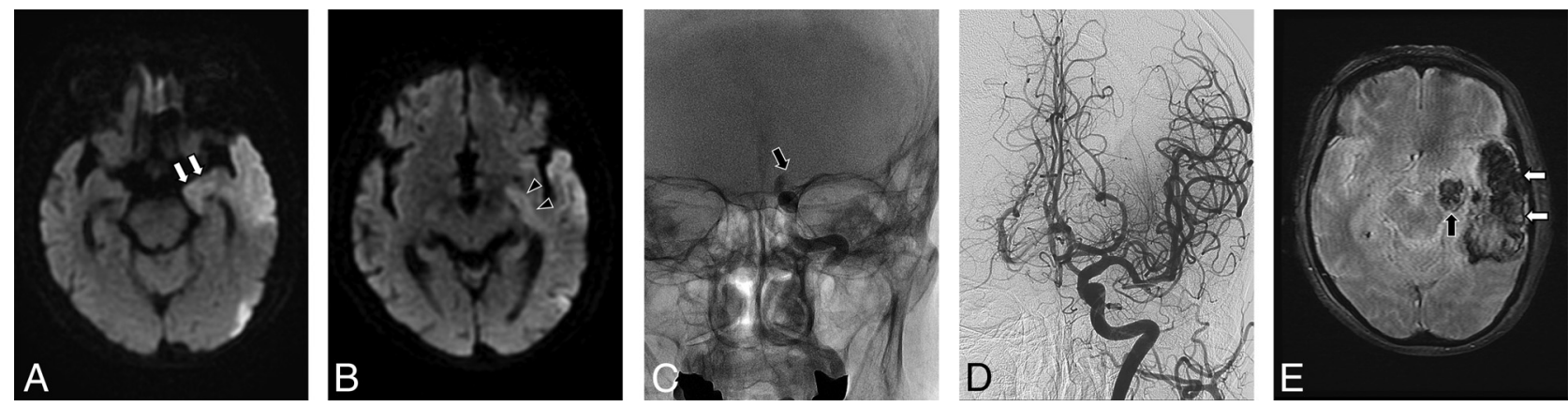

FIG 1. A 74-year-old female patient with acute stroke due to acute intracranial ICA occlusion. DWI ( $A$ and $B$ ) shows acute infarctions involving the left medial temporal lobe (arrows), left internal capsule (arrowheads), and other parts of left temporal lobe. C, A delayed-phase radiograph obtained after a left ICA angiographic run shows complete occlusion (arrow) at the distal intracranial portion of the left ICA. D, Left ICA angiogram obtained after stent-retriever thrombectomy shows complete recanalization of the left ICA with good distal perfusion. $E$, Gradientecho MR image obtained 1 day after thrombectomy shows parenchymal hematomas in the left medial temporal lobe (black arrow) and other parts of the left temporal lobe (white arrows).

Table 3: Comparison of characteristics between patients with good and poor outcomes ${ }^{a}$

\begin{tabular}{|c|c|c|c|c|}
\hline & All Patients $(n=113)$ & Good Outcome $(n=41)$ & Poor Outcome $(n=72)$ & $P$ \\
\hline Age (yr) & 74 (63-78) & $70(62-77.5)$ & 74 (64-79.75) & .105 \\
\hline Sex, male & $53(46.9)$ & $21(51.2)$ & $32(44.4)$ & .488 \\
\hline \multicolumn{5}{|l|}{ Risk factors } \\
\hline Hypertension & $76(67.3)$ & $27(65.9)$ & $49(68.1)$ & .810 \\
\hline Diabetes mellitus & $31(27.4)$ & $8(19.5)$ & $23(31.9)$ & .154 \\
\hline Dyslipidemia & $31(27.4)$ & $13(31.7)$ & $18(25)$ & .442 \\
\hline Smoking & $25(22.1)$ & $12(29.3)$ & $13(18.1)$ & .167 \\
\hline Atrial fibrillation & $69(61.1)$ & $21(51.2)$ & $48(66.7)$ & .105 \\
\hline Coronary artery disease & 19 (16.8) & $10(24.4)$ & $9(12.5)$ & .104 \\
\hline Previous stroke or TIA & 16 (14.2) & $6(14.6)$ & 10 (13.9) & .913 \\
\hline Congestive heart failure & $7(6.2)$ & $4(9.8)$ & $3(4.2)$ & .253 \\
\hline Intravenous thrombolysis & $60(53.1)$ & $21(51.2)$ & $39(54.2)$ & .763 \\
\hline Anterior choroidal artery infarction on DWI & $60(53.1)$ & $15(36.6)$ & $45(62.5)$ & .008 \\
\hline DWI-ASPECTS & $7(5-8)$ & $7(5-9)$ & $6(5-8)$ & .044 \\
\hline Time to procedure (min) & $220(160-290)$ & $225(138.5-292.5)$ & $220(161.25-297.5)$ & .770 \\
\hline Procedural time (min) & $35(25-50)$ & $30(20-45)$ & $43(27.25-58.75)$ & .023 \\
\hline Time to reperfusion (min) & $253(197-337)$ & $252(173-338)$ & $258(200.75-358)$ & .429 \\
\hline Baseline NIHSS score & 14 (11-17) & $13(10-17)$ & $15(12-17)$ & .182 \\
\hline Underlying severe intracranial stenosis & $12(10.6)$ & $8(19.5)$ & $4(5.6)$ & .028 \\
\hline Cervical ICA tandem occlusion & $10(8.8)$ & $3(7.3)$ & $7(9.7)$ & .745 \\
\hline Stroke etiology & & & & .411 \\
\hline Cardioembolism & $74(65.5)$ & $24(58.5)$ & $50(69.4)$ & \\
\hline Large-artery atherosclerosis & $18(15.9)$ & $10(24.4)$ & $8(11.1)$ & \\
\hline Undetermined & $19(16.8)$ & $5(12.2)$ & $14(19.4)$ & \\
\hline Other & $2(1.8)$ & $2(4.9)$ & 0 & \\
\hline Successful reperfusion & $89(78.8)$ & $39(95.1)$ & $50(69.4)$ & .001 \\
\hline Parenchymal hemorrhage & $8(7.1)$ & 0 & 8 (11.1) & .049 \\
\hline Symptomatic hemorrhage & $4(3.5)$ & 0 & $4(5.6)$ & .295 \\
\hline
\end{tabular}

${ }^{a}$ Values are presented as No. (\%) or median (IQR).

rhage in the basal ganglia and lobar hemorrhages. Therefore, all 8 patients developed parenchymal hemorrhage in the basal ganglia. The epicenter of hematoma was the basal ganglia in 6 patients, the lateral temporal lobe in 1 patient, and the frontal lobe in 1 patient. We found no significant differences between the 2 groups in terms of successful reperfusion, symptomatic hemorrhage, and 90-day mortality. Of 21 patients with anterior choroidal artery infarction confined to the medial temporal lobe, $19.1 \%(4 / 21)$ had good outcomes. In the group positive for anterior choroidal artery infarction, there was no statistically significant difference in the rate of good outcome between patients with internal capsule involvement and those without it $(20.8 \%$ versus $27.8 \%, P=.543)$.

\section{Predictors of Clinical Outcomes}

Comparisons of baseline characteristics and treatment outcomes according to 90-day functional outcome are shown in Table 3. In univariate analysis, the following baseline or procedural variables were associated with a good 90-day outcome: absence of anterior choroidal artery territory infarction $(P=.008)$, higher DWIASPECTS $(P=.044)$, shorter procedural time $(P=.023)$, presence of underlying severe intracranial stenosis $(P=.028)$, and successful reperfusion $(P=.001)$.

In multivariate logistic regression analysis adjusted for potential confounders (age, baseline NIHSS score, anterior choroidal artery infarction, DWI-ASPECTS, procedural time, underlying severe intracranial stenosis, and successful reperfusion), anterior 
choroidal artery infarction (OR, 0.333; 95\% CI, 0.135- $0.824 ; P=$ .017 ; Fig 2) and successful reperfusion (OR, 5.598; 95\% CI, 1.13527.604; $P=.034$; Fig 3 ) were independent predictors of a good outcome at 90 days (Table 4 ).

In subgroup analysis including only 89 patients with successful reperfusion, the following baseline or procedural variables were associated with a good 90-day outcome in the univariate analysis: absence of anterior choroidal artery territory infarction $(P=$ $.004)$ and higher DWI-ASPECTS $(P=.032)$. In multivariate logistic regression analysis adjusted for potential confounders (age, baseline NIHSS score, anterior choroidal artery infarction, and DWI-ASPECTS), absence of anterior choroidal artery territory infarction was the only independent predictor of a good 90-day outcome (OR, 0.291; 95\% CI, 0.114-0.742; $P=.010$ ) in this subgroup.

\section{DISCUSSION}

The present study found that anterior choroidal artery infarction commonly occurs in the early period of acute stroke ( $\leq 6$ hours) due to intracranial ICA occlusion at a rate of 53.1\%. In addition, anterior choroidal artery infarction seen on pretreatment DWI was significantly associated with a poor 90-day functional outcome and the occurrence of parenchymal hemorrhage following endovascular thrombectomy in this patient group. Furthermore, an absence of anterior choroidal artery infarction and successful reperfusion were independent predictors of a good 90-day outcome following endovascular thrombectomy in patients with acute intracranial ICA occlusion.

The incidence and topography of anterior choroidal artery infarction in patients with intracranial ICA occlusion who undergo endovascular thrombectomy have not been reported previously, to our knowledge. Our study showed that anterior choroidal artery infarction might occur in approximately half of patients with acute occlusion of the intracranial ICA. Even when the origin of the anterior choroidal artery is occluded in patients with intracranial ICA occlusion, anterior choroidal artery territory infarction may be absent or minimized due to collateral flows from the ipsilateral posterior communicating artery, proximal

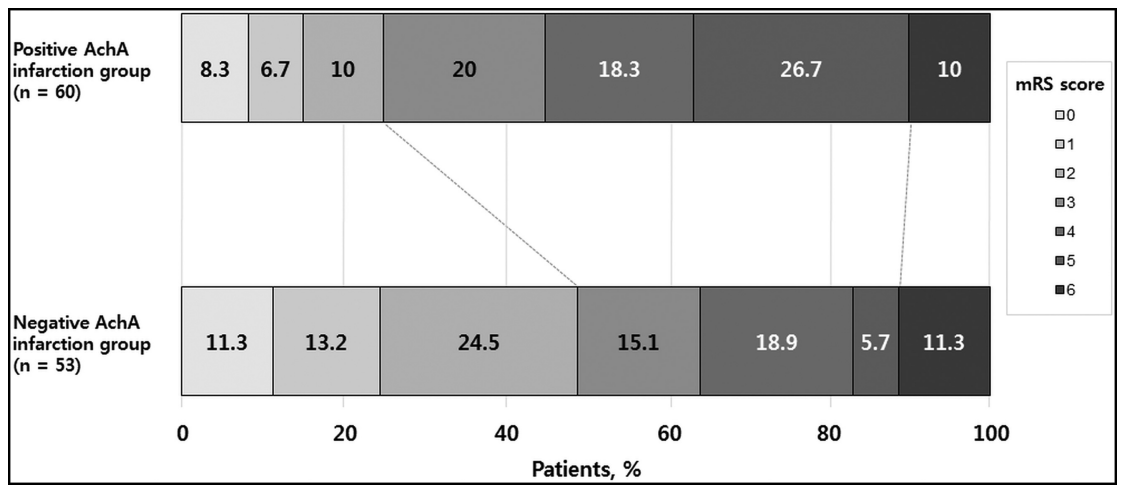

FIG 2. Distribution of mRS scores at 90 days according to the presence or absence of anterior choroidal artery infarction after thrombectomy in patients with acute intracranial ICA occlusion.

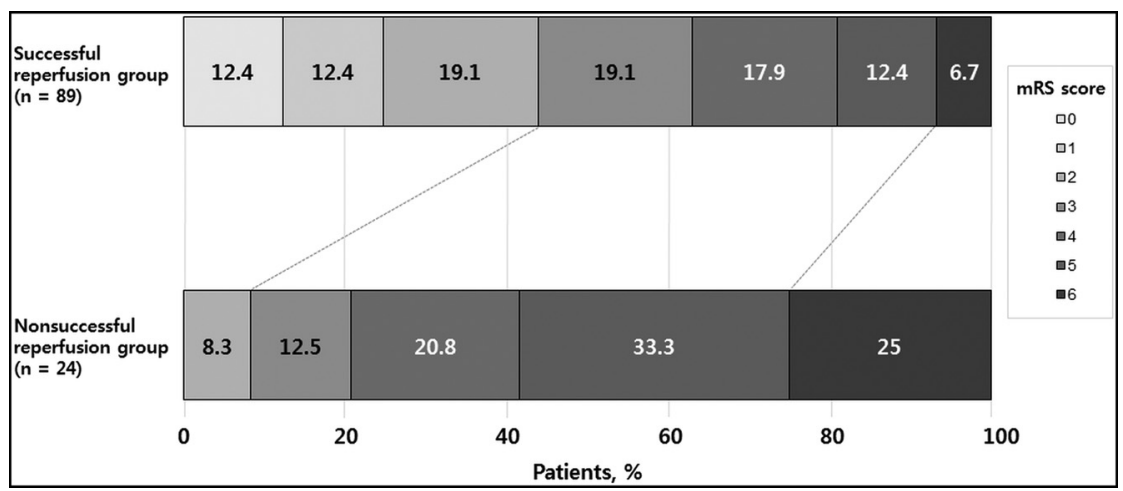

FIG 3. Distribution of mRS scores at 90 days, according to the reperfusion status after thrombectomy in patients with acute intracranial ICA occlusion. posterior cerebral artery, temporal and hippocampal branches of the posterior cerebral artery, or the posterior choroidal artery. ${ }^{14,15}$ With regard to vascular topography, the medial temporal lobe, including the uncus and amygdala, was the most frequently affected region among patients with anterior choroidal artery infarction in our study, followed by the posterior limb of the internal capsule, tail of the caudate nucleus, optic radiation, lateral thalamus, medial pallidum, hippocampus, and cerebral peduncle. The infarct topography of anterior choroidal artery infarction may also vary according to the anatomic variation and degree of collateral flow. Our study suggests that the medial temporal lobe is the most consistent region supplied from the anterior choroidal artery (95\% in our study) and is the region that may have the poorest collateral circulation.

Our study showed that anterior choroidal artery infarction on pretreatment DWI is associated with poor outcomes in patients with acute ICA occlusions even when successful reperfusion was achieved with endovascular thrombectomy. In the present study, good out-

Table 4: Univariate and multivariate binary logistic regression analysis for predictors of good 90-day outcome

\begin{tabular}{|c|c|c|c|c|}
\hline Variable & Unadjusted OR ( $95 \% \mathrm{Cl})$ & $P$ & Adjusted OR ( $95 \% \mathrm{CI})$ & $P$ \\
\hline Age, per 1-year increase & $0.975(0.942-1.009)$ & .149 & - & - \\
\hline Baseline NIHSS score, per 1-point increase & $0.922(0.834-1.019)$ & .112 & - & - \\
\hline Anterior choroidal artery infarction & $0.346(0.156-0.766)$ & .009 & $0.333(0.135-0.824)$ & .017 \\
\hline DWI-ASPECTS, per 1-point increase & $1.232(1.004-1.511)$ & .046 & - & - \\
\hline Procedure duration, per 1-min increase & $0.980(0.961-1.000)$ & .047 & - & - \\
\hline Underlying severe intracranial stenosis & $4.121(1.157-14.678)$ & .029 & - & - \\
\hline Successful reperfusion & $8.580(1.901-38.718)$ & .005 & $5.598(1.135-27.604)$ & .034 \\
\hline
\end{tabular}


comes were less frequent in the group positive for anterior choroidal artery infarction than in the group negative for it for the entire cohort (25\% versus $49 \%, P=.008$ ) and the subgroup of patients with successful reperfusion $(28.9 \%$ versus $59.1 \%, P=$ $.004)$. In addition, anterior choroidal artery infarction was an independent predictor of outcome on multivariate analyses performed in the entire cohort as well as in the subgroup with successful reperfusion. These findings may not be surprising because the anterior choroidal artery supplies deeply located eloquent areas, such as the internal capsule, amygdala, medial pallidum, thalamus, and hippocampus. Ois et $\mathrm{al}^{6}$ reported that $45.2 \%$ of patients with an isolated large (largest diameter, $\geq 2 \mathrm{~cm}$ ) anterior choroidal artery territory infarction without hemispheric infarction had poor outcomes (mRS 3-6) at 3 months. Recently, Rosso et $\mathrm{al}^{16}$ also found that the involvement of the internal capsule was the strongest predictor of 90-day outcome among DWI-ASPECTS brain regions in patients with left-sided strokes. However, there was no statistically significant difference in the rate of good outcome between patients with internal capsule involvement and those without it $(P=.543)$ among patients with pretreatment anterior choroidal artery infarction in our study. This finding may suggest that poor outcomes in the group positive for anterior choroidal artery infarction are mediated not only by the involvement of the internal capsule but also by other factors such as large baseline infarct extent, poor collateral circulation, or development of posttreatment hemorrhage in this group. In the current study, poor outcomes in patients with anterior choroidal artery infarction can be partly attributed to the occurrence of parenchymal hemorrhage, which is known to be a predictor of poor outcomes and mortality after endovascular thrombectomy in patients with anterior circulation large-vessel occlusion. ${ }^{2,17}$ This hemorrhage occurred only in patients with anterior choroidal artery infarction in our study, which may suggest that patients with anterior choroidal artery infarction have a severely hypoperfused lesion due to poor collateral status. ${ }^{18}$

To date, only 1 study has investigated the relationship between anterior choroidal artery infarction and functional outcome in patients with ICA occlusion. Lee et $\mathrm{al}^{7}$ reported that the absence of anterior choroidal artery infarction or infarction restricted to the medial temporal lobe, compared with other patterns of infarction, had a good discharge outcome (44.4\% versus $12.1 \%)$ more frequently among 60 patients with ICA occlusions. In our study, only $19 \%$ of patients with anterior choroidal artery infarction confined to the medial temporal lobe had good outcomes at 90 days, which seems to be inconsistent with the results of the study of Lee et al. Apart from the inequality of the compared groups and endovascular treatment technique, this discrepancy may be due, in large part, to the differences in the timing of the outcome assessment (90-day versus discharge) and the proportions of stroke subtypes between the 2 studies. Anterior choroidal artery infarction tends to result in neurologic symptom progression, ${ }^{19}$ and cardioembolism was more common in our study than the study of Lee et al.

Yoon et $\mathrm{al}^{2}$ reported that age, reperfusion status, parenchymal hemorrhage, and baseline NIHSS score were independent predictors of good outcome in 335 patients with acute anterior circulation stroke who underwent modern endovascular thrombec- tomy. Among patients with acute anterior circulation stroke, those with ICA occlusions have a worse prognosis than those with MCA occlusions, even after endovascular thrombectomy. Therefore, the identification of more specific predictors directly related to ICA occlusions is needed to further improve patient management in acute anterior circulation stroke. However, such investigations have not been reported to date. Our study revealed that pretreatment anterior choroidal artery infarction independently predicts functional outcome after endovascular thrombectomy in acute ICA occlusions. Moreover, anterior choroidal artery infarction was independently associated with 90-day outcome regardless of reperfusion status. This finding suggests that performing DWI before thrombectomy is advantageous in the prognostication of patients with acute ICA occlusion because it is challenging to identify acute ischemic changes within the anterior choroidal artery territory with CT in the hyperacute stage. Our study also confirmed the strong association of successful reperfusion and good outcomes after endovascular thrombectomy in acute largevessel occlusion, which has been observed in previous studies. ${ }^{2,3}$ In our study, a good outcome was achieved in $44 \%(n=39 / 89)$ of patients with successful reperfusion, but only in $8.3 \%(n=2 / 24)$ of patients without successful reperfusion in the entire cohort. Successful reperfusion was one of the independent predictors of good 90-day outcome (OR, 8.305). Although the rate of successful reperfusion was higher in our study than in previous reports $(79 \%$ in our study versus $69 \%$ in a pooled analysis including 115 patients ${ }^{1}$ ), this rate is unsatisfactory. Considering the importance of successful reperfusion, a more effective endovascular strategy is still needed for patients with acute ICA occlusions.

This study had some limitations. First, this was a retrospective study conducted in a single center. Second, we could not evaluate collateral circulation in this study because contralateral ICA and vertebral angiography were not performed according to our protocol for acute stroke intervention. In addition, the length of occlusion in the ICA, A1 segment of the anterior cerebral artery, and the M1 segment of the MCA could not be evaluated because microcatheter contrast injection was usually not recommended during an endovascular procedure to decrease hemorrhagic complications. $^{20}$

\section{CONCLUSIONS}

Our study suggests that anterior choroidal artery infarction is common during the early period after occlusion of the intracranial ICA, and pretreatment anterior choroidal artery infarction is associated with parenchymal hemorrhage and poor 90-day outcome after modern endovascular thrombectomy. In addition, this study revealed that an absence of anterior choroidal artery infarction and successful reperfusion are significant predictors of good outcomes after thrombectomy in acute intracranial ICA occlusions.

\section{REFERENCES}

1. Kappelhof M, Marquering HA, Berkhemer OA, et al. Intra-arterial treatment of patients with acute ischemic stroke and internal carotid artery occlusion: a literature review. J Neurointerv Surg 2015; 7:8-15 CrossRef Medline

2. Yoon W, Kim SK, Park MS, et al. Predictive factors for good outcome and mortality after stent-retriever thrombectomy in patients 
with acute anterior circulation stroke. J Stroke 2017;19:97-103 CrossRef Medline

3. Dekker L, Geraedts VJ, Hund H, et al. Importance of reperfusion status after intra-arterial thrombectomy for prediction of outcome in anterior circulation large vessel stroke. Interv Neurol 2018;7: 137-47 CrossRef Medline

4. Levy R, Duyckaerts C, Hauw JJ. Massive infarcts involving the territory of the anterior choroidal artery and cardioembolism. Stroke 1995;26:609-13 CrossRef Medline

5. Palomeras E, Fossas P, Cano AT, et al. Anterior choroidal artery infarction: a clinical, etiologic and prognostic study. Acta Neurol Scand 2008;118:42-47 Medline

6. Ois A, Cuadrado-Godia E, Solano A, et al. Acute ischemic stroke in anterior choroidal artery territory. J Neurol Sci 2009;281:80-84 CrossRef Medline

7. Lee M, Saver JL, Hao Q, et al; UCLA Stroke Investigators. Anterior choroidal artery ischaemic patterns predict outcome of carotid occlusion. J Neurol Neurosurg Psychiatry 2012;83:586-90 CrossRef Medline

8. Sohn H, Kang DW, Kwon SU, et al. Anterior choroidal artery territory infarction: lesions confined to versus beyond the internal capsule. Cerebrovasc Dis 2013;35:228 -34 CrossRef Medline

9. Yoon W, Jung MY, Jung SH, et al. Subarachnoid hemorrhage in a multimodal approach heavily weighted toward mechanical thrombectomy with Solitaire stent in acute stroke. Stroke 2013;44:414-19 CrossRef Medline

10. Kim SK, Yoon W, Moon SM, et al. Outcomes of manual aspiration thrombectomy for acute ischemic stroke refractory to stent-based thrombectomy. J Neurointerv Surg 2015;7:473-77 CrossRef Medline

11. Zaidat OO, Yoo AJ, Khatri P, et al; Cerebral Angiographic Revascularization Grading (CARG) Collaborators, STIR Revascularization Working Group, STIR Thrombolysis in Cerebral Infarction (TICI) Task Force. Recommendations on angiographic revascularization grading standards for acute ischemic stroke: a consensus statement. Stroke 2013;44:2650-63 CrossRef Medline
12. Larrue V, von Kummer R, Müller A, et al. Risk factors for severe hemorrhagic transformation in ischemic stroke patients treated with recombinant tissue plasminogen activator: a secondary analysis of the European-Australasian Acute Stroke Study (ECASS II). Stroke 2001;32:438-41 CrossRef Medline

13. Adams HP Jr, Bendixen BH, Kappelle LJ, et al. Classification of subtype of acute ischemic stroke: definitions for use in a multicenter clinical trial-TOAST. Trial of Org 10172 in Acute Stroke Treatment. Stroke 1993;24:35-41 CrossRef Medline

14. Takahashi S, Suga T, Kawata Y, et al. Anterior choroidal artery: angiographic analysis of variations and anomalies. AJNR Am J Neuroradiol 1990;11:719-29 Medline

15. Takahashi S, Tobita M, Takahashi A, et al. Retrograde filling of the anterior choroidal artery: vertebral angiographic sign of obstruction in the carotid system. Neuroradiology 1992;34:504-07 CrossRef Medline

16. Rosso C, Blanc R, Ly J, et al; ASTER Trial and Pitié-Salpêtrière Investigators. Impact of infarct location on functional outcome following endovascular therapy for stroke. J Neurol Neurosurg Psychiatry 2019; 90:313-19 CrossRef Medline

17. Nogueira RG, Gupta R, Jovin TG, et al. Predictors and clinical relevance of hemorrhagic transformation after endovascular therapy for anterior circulation large vessel occlusion strokes: a multicenter retrospective analysis of $\mathbf{1 1 2 2}$ patients. J Neurointerv Surg 2015;7: 16-21 CrossRef Medline

18. Mishra NK, Christensen S, Wouters A, et al; DEFUSE 2 Investigators. Reperfusion of very low cerebral blood volume lesion predicts parenchymal hematoma after endovascular therapy. Stroke 2015;46: 1245-49 CrossRef Medline

19. Derflinger S, Fiebach JB, Böttger S, et al. The progressive course of neurological symptoms in anterior choroidal artery infarcts. Int $J$ Stroke 2015;10:134-37 CrossRef Medline

20. Khatri R, Khatri P, Khoury J, et al. Microcatheter contrast injections during intra-arterial thrombolysis increase intracranial hemorrhage risk. J Neurointerv Surg 2010;2:115-19 CrossRef Medline 